\title{
ENTREVISTA COM FREDA INDURSKY
}

INTERVIEW WITH FREDA INDURSKY

\author{
Freda Indursky ${ }^{1}$, Andréa Rodrigues ${ }^{2}$ \\ ${ }^{1}$ Universidade Federal do Rio Grande do Sul (UFRGS), Porto Alegre, RS, Brasil \\ freda.indursky@gmail.com \\ ${ }^{2}$ Universidade do Estado do Rio de Janeiro (UERJ), São Gonçalo, RJ, Brasil \\ andrearodrigues.letras@gmail.com
}

Entrevista concedida em 16 dez. 2019

Andréa Rodrigues - No texto Estudos da linguagem: a leitura sob diferentes olhares teóricos ${ }^{1}$, você faz uma crítica ao fato de, para a escola, quase sempre, saber ler corresponderia somente a saber extrair informações do texto. Como formar professores, nos cursos de graduação em Letras e/ou Educação, que contribuam para desnaturalizar essa noção de leitura?

Freda Indursky - Penso que o professor antes de mais nada deve ser um leitor que não se limite a reproduzir os sentidos apresentados pelo texto. $O$ que se espera de um professor é que ele seja um leitor crítico. E sua formação nos cursos de Letras deve dar-lhe base para tornar-se um sujeito que reflete sobre o que lê. Se as disciplinas de seu currículo privilegiarem perguntas do tipo conteudístico como "o que o autor quis dizer?" e outras semelhantes, baseadas nas noções de texto completo e fechado em si mesmo e de literalidade do sentido, possivelmente se tornará um leitor que busca a resposta exclusivamente no texto. E, ao tornar-se professor, reproduzirá esse modelo, do qual decorre uma leitura com limites, determinados pela ilusão de completude da linguagem e do texto. Para quebrar este ciclo vicioso, é preciso inicialmente trabalhar diferentes concepções teóricas de texto, de leitura e de escrita com base nas Teorias do Texto, Teoria da Análise do Discurso, Teorias da Enunciação etc., para, posteriormente, produzir atividades que conduzam esses estudantes a ler/interpretar/escrever sob esses diferentes olhares teóricos. Só assim haverá uma transformação na forma como a leitura é praticada na escola, visando a uma prática reflexiva.

Não defendo a eliminação de perguntas que exploram o texto, pois para interpretar é preciso antes compreender o que o texto propõe. Entendo que perguntas de compreensão sejam o ponto de partida necessária para que o leitor possa, a seguir, ultrapassar esse estágio de leitura e posicionar-se, de modo que essas perguntas devem ser seguidas de questões que levem à reflexão, que

\footnotetext{
${ }^{1}$ INDURSKY, F. Estudos da linguagem: a leitura sob diferentes olhares teóricos. In: TFOUNI, L. V. (org.). Letramento, escrita e leitura. Campinas: Mercado de Letras, 2010. p. 163-178.
} 
coloquem o texto em relação com outros textos, outros pontos de vista, rompendo as fronteiras físicas que o separam da exterioridade. Ou seja: caso o professor trabalhe com livro didático e este não ofereça esse tipo de leitura, caberá ao professor formular perguntas interpretativas ou atividades complementares que façam o aluno refletir sobre o que o texto defende. É imperioso que o futuro professor perceba que interpretação não é sinônimo de compreensão. Interpretar implica reconhecer a opacidade da linguagem e trabalhar com ela. Esse professor em formação deve entender que a interpretação inicia na compreensão do texto, mas vai além de suas fronteiras. Interpretar implica igualmente tomada de posição por parte do sujeitoleitor frente ao texto, a qual não é obrigatoriamente uma reprodução da posição assumida pelo autor do texto que está sendo lido. Ou seja, interpretar implica a realização de uma leitura que não seja exclusivamente parafrástica. Ao interpretar, o sujeito-leitor pode recuar, questionar, resistir, duvidar da posição defendida no texto. E o faz a partir de seu lugar social, que é ideológico, e que não coincide obrigatoriamente com o lugar social do sujeito-autor. Para que esse exercício funcione, entretanto, é necessário mobilizar textos que se prestem a diferentes posicionamentos. Vale dizer: textos que defendam pontos de vista em detrimento de outros possíveis. Assim, estará sendo produzida uma pratica de leitura reflexiva que inscreva o sujeito como sujeito-leitor. E, sobre isso, ainda há que considerar três diferentes aspectos. Inicialmente, é preciso pensar que não é de imediato que o aluno passa de leitor-reprodutor a sujeito-leitor. Essa passagem se faz praticando.

Segunda observação: ninguém ensina ninguém a ler. Ler se aprende lendo. Por fim, ler não implica tudo ou nada, mas diferentes graus de leitura que conduzem da leitura parafrástica à leitura crítica e políssêmica. Esses graus de leitura indicam que há, por um lado, a leitura idealizada pelo professor e, por outro, a leitura possível para os alunos. É essa leitura possível que serve de guia ao professor em sua prática docente na preparação das atividades de leitura que possibilitem ao sujeito-aluno exercitar-se na prática da leitura e avançar em direção a tornar-se um sujeito-leitor. Ou seja: ninguém ensina ninguém a ler, é verdade, mas professores bem formados dispõem dos instrumentos teóricos necessários para produzir práticas em sala de aula que propiciem ao aluno crescer em sua prática leitora e tornar-se um leitor reflexivo.

A. R. - Em texto publicado em 2011 - Discurso, língua e ensino: especificidades e interfaces $^{2}-$, você propõe que é possível a um professor de língua mobilizar a

\footnotetext{
${ }^{2}$ INDURSKY, F. Discurso, língua e ensino: especificidades e interfaces. In: TFOUNI, L. V.; MONTESERRAT, D. M.; CHIARETTI, Paula. (org.). A análise do discurso e suas interfaces. São Carlos: Pedro \& João, 2011a. p. 327-340.
} 
Análise do Discurso em sala de aula e promover análises sobre os funcionamentos linguístico e discursivo das formas da língua. Esse tipo de prática de ensino faria com que o aluno pudesse refletir sobre a língua e o que se faz com ela em práticas discursivas. De que modo o aporte teórico da $A D$ poderia também contribuir para um trabalho, em sala de aula, que promovesse reflexões sobre as chamadas fake news?

F. I. - Diria, para iniciar, que uma discussão sobre fake news poderia levar a pensar em uma reflexão sobre falso e verdadeiro. De onde decorre um questionamento: essa questão faz sentido no âmbito da Análise do Discurso? Frente ao fato de que a discursivização do político implica, sempre, relações de poder, mediadas por diferentes forças ideológicas, penso que o discurso das fake news estabelece uma forma muito peculiar de relação com o político, atravessada pela ideologia, à qual associam-se memória, formações imaginárias e silêncio, pois, como nos alerta Orlandi $^{3}$, "as palavras [...] são atravessadas pelo silêncio". Isso implica dizer que o silêncio é constitutivo da espessura da linguagem, possibilitando a emergência de deslizamentos de sentido que sustentam o discurso das fake news. Portanto, não se trata de colocar o foco na lógica. Bem ao contrário. O que estará em tela será o processo semântico que se produz na construção discursiva das notícias falsas.

Trata-se de uma discursividade que exige interpretação, pois essa prática se reveste e joga com a opacidade da linguagem de que as fake news se revestem em sua materialização para produzir um efeito de verdade ${ }^{4}$. A circulação das falsas notícias causa impacto pelo que divulga, por um lado, e, por outro, joga com uma memória fluida - esburacada, atravessada pelo esquecimento e pelo desconhecimento - com que o leitor/espectador vai ler essa falsa noticia. Em função disso, creio que as falsificações e seu uso político encontram espaço para serem analisadas à luz da AD.

Pensar fake news implica, em primeiro lugar, constatar que essa é uma prática que existe desde a antiguidade. Courtine ${ }^{5}$, em 0 Mentir Verdadeiro, salienta que Platão em $A$ República já se referia à arte de ocultar a verdade ao povo. Também Maquiavel refletiu sobre "a arte de fazer o povo acreditar em falsidades salutares". $O$ que mudou, em nossos dias, foi a designação: a mentira foi renomeada e passou a ser referida como fake news. Mas não só, como veremos mais adiante.

\footnotetext{
${ }^{3}$ ORLANDI, E. As formas do silêncio. No movimento dos sentidos. Campinas: Editora da UNICAMP, 1992.

${ }^{4}$ INDURSKY, F. O momento político brasileiro e sua discursivização em diferentes espaços midiáticos. In: FLORES, G.; GALLO, S.; LAGAZZI, S.; NECKEL, N.; ZOPPI-FONTANA, M. (org.) Análise de discurso em rede: cultura e mídia. V. 3. Campinas: Pontes, 2017. p. 73-87.

${ }^{5}$ COURTINE, J. J. O mentir verdadeiro (Prefácio). In: SWIFT, J. A arte da mentira política. Tradução de Mônica Zoppi-Fontana e Roberto L. Baronas. Campinas: Pontes, 2006.
} 
Antes, porém, vale lembrar de uma variação das falsas notícias, muito popular e bem anterior a elas, o boato ${ }^{6}$. $O$ boato é uma prática discursiva que funciona na modalidade do anonimato, onde o sujeito que o enuncia abriga-se para produzir sua versão dos fatos ou criar falsas narrativas.

Mas o que distingue boatos de falsificações? Em primeiro lugar, as Condições de Produção de sua circulação. A circulação do boato consiste na transmissão boca a boca de uma narrativa. Algo como "Dizem que o fulano fez X", ou, ainda, "Andam comentando que aconteceu Y", etc. A marca linguística do boato é, pois, a indeterminação do sujeito linguístico da frase: dizem, estão dizendo, circula por aí.... Essa indeterminação linguística projeta-se sobre o sujeito do discurso e o coloca ao abrigo do anonimato, pois o boateiro sempre poderá alegar que não é a fonte desse diz-que-diz-que, que apenas está repetindo o que ouviu. Dessa forma, o boato vai construindo oralmente um zum-zum-zum social pelo qual ninguém se responsabiliza. Esse é o funcionamento discursivo do boato: produzir ruído.

Atualmente, com as fake news, as condições de produção de circulação são outras. Hoje, vivemos conectados à internet e é nela que as fake news circulam. $\mathrm{O}$ boca a boca foi substituído pelo compartilhamento nas diversas redes sociais em que o sujeito se inscreve e essas falsas notícias, nesse meio eletrônico, ganham velocidade na circulação e na multiplicação dos destinatários que, por sua vez, também passam a compartilhar essas falsificações. Ou seja, as redes sociais potencializaram enormemente a quantidade e a velocidade na divulgação das falsas notícias. E não estou levando em consideração, aqui, os robôs que foram mobilizados nas últimas eleições presidenciais nos Estados Unidos e, ao que tudo indica, no Brasil também. Essas são as condições de produção de circulação das fake news.

Paralelamente ao modo de circulação, faz-se necessário observar as condições específicas de produção desse tipo de prática discursiva. Ela caracterizase por não apresentar marcas linguísticas específicas, distinguindo-se formalmente do boato. As fake news frequentemente assumem forma idêntica à de uma matéria jornalística, sendo formuladas na modalidade de discurso sobre. A diferença entre 0 discurso de uma matéria jornalística e o discurso de uma fake news é que a responsabilidade pela primeira é do jornalista ou do jornal que a veicula, enquanto ignora-se frequentemente a fonte da falsa notícia. Mas as fake news podem assumir igualmente outras formas, tais como memes, vídeos, fotos, notícias, declarações. $\mathrm{O}$

\footnotetext{
${ }^{6}$ Orlandi, em Discurso e texto [ORLANDI, E. Discurso e texto. Campinas: Pontes, 2001], tratou em profundidade da prática do boato. Aqui essa prática entra apenas para fazer um contraponto com as Fake News.
} 
alvo das fake news pode ser muito variado, incidindo sobre política, políticos, ciência, verdades estabelecidas etc.

As fake news, sob o efeito da ideologia, ao mesmo tempo em que produzem uma falsificação, projetam sobre ela um imaginário efeito de verossimilhança. Esse é seu ponto fulcral. Esse efeito produz um rumor social muito intenso decorrente do impacto que elas causam. E quando essas falsificações incidem sobre uma campanha eleitoral, por exemplo, esse rumor pode trazer como consequência a eleição ou a derrota de um candidato. Eis a diferença entre o ruído dos boatos e rumor ensurdecedor das fake news.

Em decorrência do que precede, é necessário também refletir sobre as condições de produção da prática de leitura dessas fake news. O leitor, de modo geral, ao ler uma matéria, acerca-se dela, mergulhado no que tenho chamado de uma memória fluida, que se caracteriza por ser difusa e esburacada, marcada pela vagueza, pelo imaginário e pelo desconhecimento. Assim, diante de um texto dado a ler como notícia, o leitor não parte do pressuposto de que a matéria pode ser falsa, bem ao contrário. Essa é uma circunstância determinante das condições de produção da prática de leitura de fake news: o leitor, via de regra, não desconfia do discurso sobre, que vem revestido do efeito de verdade, razão pela qual compartilha a falsa notícia, seja porque identifica-se com ela, seja porque dela discorda. De modo que a mola propulsora do leitor/espectador comum, não aquele que produz, mas o que compartilha as falsas notícias é o desconhecimento, por um lado, e a ordem dos afetos, por outro.

Por outro lado, os sujeitos leitores, ao colocarem as falsificações em circulação em suas redes sociais, tornam-se responsáveis pelo que veiculam e, assim procedendo, assumem algo muito próximo da função-autor ${ }^{7}$ da falsa notícia que estão compartilhando, pois the aportam credibilidade e, por conseguinte, reforçam seu efeito de verossimilhança que advém do regime de repetibilidade ${ }^{8}$ decorrente da circulação vertiginosa nas diferentes redes sociais.

Se a mobilização de notícias falsas não é novidade no campo da política, como exposto mais acima, essa prática discursiva na atualidade passou a ter um peso muito grande no discurso político e no modo de fazer política atuais. Em função das novas tecnologias da informação e das facilidades que elas trouxeram, aliadas ao possível anonimato que propiciam, a prática de falsificação deliberada de arquivos e distorções de fatos tornou-se moeda corrente.

\footnotetext{
7 ORLANDI, E. Discurso e leitura. São Paulo: Cultrix, 1988.

8 INDURSKY, F. A memória na cena do discurso. In: INDURSKY, F.; FERREIRA, M. C. L.; MITTMANN, S. (org.). História e memória na/da análise do discurso. Campinas: Mercado de Letras, 2011b. p. 67-90.
} 
Vou fazer uma breve análise, a partir de uma discussão que se desenrolou durante a campanha para as eleições presidenciais de 2018. O caso que vou analisar não se reveste de anonimato, como veremos a seguir. Essa questão, na verdade, iniciou-se bem antes, com a campanha pela Escola sem Homofobia, quando Haddad ainda era Ministro da Educação. Durante a última campanha eleitoral para a Presidência do Brasil, a proposta de Haddad foi retirada do arquivo e, sob a ação da ideologia, foi distorcida. Por outro lado, as formações imaginárias projetadas sobre os possíveis eleitores desse candidato também desempenharam um papel importante. O candidato que se opunha a Haddad passou a acusá-lo de ter querido introduzir nas escolas infantis um kit gay e, enquanto afirmava isto, brandia no ar o livro infanto-juvenil $O$ aparelho sexual \& cia. Assim, um projeto, que tinha por objetivo trabalhar nas escolas o respeito à diversidade de gênero e que nem chegou a ser implantado, foi recuperado, distorcido e apresentado como uma prova de que Haddad queria naturalizar a prática da homossexualidade junto a crianças de 6 anos de idade. Houve, pois, um deslizamento facultado pela espessura semântica da linguagem. Essa notícia falsa construiu-se com base na proximidade semântica entre escola sem homofobia e os materiais que seriam elaborados para desenvolver esse projeto, entre eles uma cartilha. Assim, os sentidos deslizaram de cartilha e demais materiais para kit gay para as escolas. Essa falsa proximidade, propiciada pela opacidade da língua, por um lado e, por outro, pela similitude do campo semântico da qual a falsa notícia se alimentou, produziu a verossimilhança necessária para formular um discurso que soasse como "verdadeiro". Essa é a natureza do "acontecimento" que impacta/indigna o leitor/espectador, induzindo-o a confiar e aceitar como verdade aquela falsificação e a repassá-la.

Analisar fake news implica, pois, trabalhar com a opacidade da linguagem e a espessura do discurso para alcançar o funcionamento do político que nelas se materializa. Como disse anteriormente, o discurso dessa fake news não foi produzido ao abrigo do anonimato. Bem ao contrário. O antagonista de Haddad, em sua luta pelo poder, repetiu-a mais de uma vez frente às câmaras de TVs, deixando à mostra seu modo cínico $0^{9}$ de identificar-se com a ideologia ${ }^{10}$ para desacreditar seu adversário.

\footnotetext{
${ }^{9}$ ŽlŽZEK, S. Como Marx inventou o sintoma? In: ŽlŽZEK, S. (org.). Um mapa da ideologia. Rio de Janeiro: Contraponto, 1996. p. 227-331.

${ }_{10}$ INDURSKY, F. Os (des)caminhos do discurso político brasileiro na contemporaneidade. In: GRIGOLETTO, E.; DE NARDI, F. S. (org.). Análise do Discurso e sua história: avanços e perspectivas. Campinas: Pontes, 2016. p. 65-88.
} 
Vejamos mais de perto o processo de produção do discurso das fake news. Elas se constroem pelo viés de torções discursivas ${ }^{11}$ realizadas sob o efeito da desidentificação ideológica com o que está sendo falsificado. No caso em análise, o sujeito produtor daquela fake news não se identifica com a proposta de discutir diversidade de gêneros na escola. $E$, em função disso, produz uma falsificação. A torção discursiva consiste em projetar um efeito de verdade sobre o que, de fato, é uma falsificação de um ocorrido, de um fato, de uma declaração ou, como no caso acima examinado, de um projeto retirado do arquivo do Ministério da Educação. Vale aqui lembrar o que nos ensinou Pêcheux ${ }^{12}$ : "todo enunciado é intrinsecamente suscetível de tornar-se outro, diferente de si mesmo, de deslocar-se discursivamente de seu sentido para derivar para um outro". Diria, pois, que a fake news é o avesso da notícia que está sendo distorcida. Ambas estão separadas no tempo, em enunciados diferentes, produzidas por enunciadores diversos, mas, para apurar a falsificação, é preciso interpretá-la e cotejá-la com a notícia que foi distorcida, pois uma é a negação da outra. Dito de outra forma: a falsificação, em função da torção discursiva que a sustenta, carrega vestígios memoriais do que foi falsificado, e esses traços funcionam como uma presença-ausente. Ou seja: a análise de uma fake news consiste em seguir a trajetória do discurso falsificador em direção ao discurso falsificado para identificar a torção discursiva e, dessa forma, desfazê-la. Essa torção reúne pelo viés do discurso-transverso de que nos fala Pêcheux ${ }^{13}$ o discurso falsificado e o discurso falsificador. Dito de outra forma: o discurso falsificado faz ressoar transversamente em seu interior o discurso que foi alvo da falsificação. Essa é a trajetória discursiva que a interpretação de uma falsificação como a que analisei acima percorre.

Por isso, retomo o que explorei na resposta à primeira pergunta, mas com uma diferença. Naquela resposta, apontei que o leitor tem direito a um ponto de vista diferente ao defendido no texto que está lendo. Agora, frente às fake news, o leitor precisa aprender a duvidar da veracidade do que Ihe é dado a ler, pois a língua não é transparente e os sentidos, como sabemos, podem deslizar. E, ao entrarem em deriva, podem inscrever-se em uma formação discursiva antagônica. Frente a essas condições de produção, mais do que nunca, é preciso recuar, duvidar, questionar, refletir. Desconfiar tornou-se, hoje, uma forma importantíssima de resistência

\footnotetext{
${ }^{11}$ As primeiras formulações sobre torções discursivas estão presentes em INDURSKY, F. Entrevista. In: MARIANI, B.; SILVA, S. D. Discurso político: processos de significação em tempos de fake news uma entrevista com Freda Indursky. Caderno de Letras da UFF, Niterói, v. 30, n. 59, 2019. p. 13-31.

${ }_{12}$ PÊCHEUX, M. Ler, descrever, interpretar. In: PÊCHEUX, M. $\mathbf{O}$ discurso: estrutura ou acontecimento. Campinas: Pontes, 1990. p.43-58.

${ }^{13}$ PÊCHEUX, M. Semântica e discurso. Campinas: Editora da UNICAMP, 1988.
} 
política. Não apenas para interpretar, como minha primeira resposta indicava, mas, agora, antes disso, para avaliar se a notícia é autêntica ou falsa.

As fake news se instauram em função da memória fluida de quem as lê, por um lado e, por outro, elas jogam com funcionamentos discursivos como equívocos, deslizamentos de sentidos, efeitos de similitude, pré-construídos, discursos transversos que sustentam as falsificações e produzem efeitos de verdade. Para que as fake news "colem", elas precisam soar verossímeis. Esse é seu ponto forte e, contraditoriamente, o ponto por onde o trabalho discursivo de interpretação pode iniciar. Vale dizer: a verossimilhança não garante a autenticidade da notícia.

Penso nesse ponto como um punctum ${ }^{14}$ que pode ser verbal ou imagético. No caso analisado, é imagético-verbal, pois associa toda a parte visual do vídeo ao discurso da fake news produzido pelo então candidato. É o punctum que vai chamar a atenção por produzir um jogo entre ressonância e dissonância a um só tempo. Produz ressonância ${ }^{15}$ porque faz vibrar vestígios memoriais de algo que está fora, inscrito no interdiscurso, funcionando aí como uma memória fluida. No caso analisado mais acima, o punctum foi acionado pela presença da palavra kit que produziu ressonância com o conjunto de materiais sócio-educativos que seriam preparados para trabalhar a homofobia nas escolas. Por outro lado, o punctum, ao ressoar, pode acionar na memória fluida do leitor/espectador um estranhamento ${ }^{16}$. No caso analisado, o punctum que fez soar o estranhamento e disparou a dissonância ${ }^{17}$ foi a presença do termo gay na expressão kit gay associado ao livro 0 aparelho sexual \& cia.

A dissonância faz vibrar na memória fluida do leitor/espectador uma pergunta: isso é mesmo verdade? Diria que esse questionamento sinaliza a resistência do sujeito em aceitar aquele efeito de verdade como um fato verídico e então, a partir de sua posição de leitor crítico, passa a duvidar e buscar verificação. Essa passagem da ressonância para a dissonância se instaura em função da opacidade da língua e da espessura do discurso.

Assim, as fake news promovem processos semânticos regidos por contradições que põem em evidência a luta de classes que está sendo travada em busca do poder. Por outro lado, a falsificação que analisei mais acima expõe os

\footnotetext{
${ }^{14}$ INDURSKY, F. Cartografias geopolíticas como gesto de Resistência. In: CARROZZA, G.; SANTOS, M. dos; SILVA, T. da (org.). Sujeito, sociedade, sentidos. Campinas: RG Editores, 2012. p. 135-150. ${ }^{15}$ SERRANI, S. A linguagem na pesquisa sociocultural. Campinas: Ed. da UNICAMP, 1993.

${ }^{16}$ INDURSKY, F. O mal-estar na política e na cultura brasileiras, hoje. In: MITTMANN, S.; CAMPOS, L. J. de. (org.). Análise do Discurso: da inquietude ao incômodo lugar. Campinas: Pontes, 2019a. p. $27-42$.

${ }_{17}$ INDURSKY, F. A exterioridade constitutiva do texto à luz da análise do discurso. In: BATTISTI, E.; COLISCHONN, G. (org.). Língua e linguagem: perspectivas de investigação. Pelotas: EDUCAT, 2011c. p. $19-43$.
} 
traços moralistas e conservadores que caracterizam a formação social brasileira. Traços estes que, aliados ao desconhecimento, ajudam a compreender porque as fake news se transformam em pós-verdades ${ }^{18}$.

Penso poder afirmar que não é na forma das fake news que se encontram as marcas principais de seu funcionamento, como ocorre com os boatos, mas nos processos de significação, nas ressonâncias e dissonâncias, nos efeitos de sentido, nos deslizamentos. É através desses funcionamentos discursivos que o rumor social se instaura, o qual está na base da produção desses efeitos de realidade ${ }^{19}$ que encontram as condições ideais para instituírem o efeito de sentido de pós-verdade.

Em suma, trabalhar a prática discursiva da falsificação da notícia em sala de aula parece-me ser importante em um tempo em que a falsificação adquiriu, no fazer político de nossos dias, uma força muito grande, sinalizando que frequentemente a versão dos fatos tem tido muito mais adesão e credibilidade do que o fato propriamente dito, daí decorrendo a pós-verdade de que essas fake news se revestem. A grande questão que se coloca, pois, é suspeitar da veracidade de certas notícias. Esse é o novo e grande desafio que se coloca aos analistas de discurso e aos professores nos dias que correm.

A. R. - Ainda no texto Discurso, língua e ensino: especificidades e interfaces ${ }^{20}$, você observa que, embora a $A D$ tenha surgido com objetivos que não eram ligados ao ensino, o fazer teórico-metodológico dessa abordagem pode trazer contribuições interessantes para a reflexão sobre língua, texto, leitura e escrita. Que políticas de ensino e pesquisa seriam necessárias para fazer esse campo se expandir no Brasil, hoje?

F. I. - Para que a Análise do Discurso venha a se expandir, é necessário que os Cursos de Letras estejam empenhados em oferecer essa disciplina desde o início da graduação. Ela poderia se fazer presente em disciplinas que se proponham a refletir sobre a língua, principalmente sobre sintaxe, leitura e produção textual. Poderia entrar na forma de contraponto com outras abordagens. Penso que não é isso o que sucede na maioria das grades curriculares. E para que isso ocorra, é necessária uma outra visão de ensino e de concepções teóricas que ultrapassem o já estabelecido. Por outro lado, o professor que deseja trabalhar com Análise do Discurso pode fazê-lo, colocando em sua bibliografia textos que oportunizem

\footnotetext{
${ }^{18}$ O Oxford Dictionaries, em 2016, considerou como a palavra do ano a "pós-verdade", definindo-a como "circunstâncias em que os fatos objetivos são menos influentes em formar a opinião pública do que os apelos à emoção e à crença pessoal". Disponível em: http://www.bbc.co.uk/news/uk37995600. Acesso em: 15 dez. 2019.

${ }^{19}$ Conferir nota 4.

${ }^{20}$ Conferir nota 2.
} 
apresentar o modo como a AD trabalha e cotejá-lo com os demais. Ou seja: trabalhar com a $A D$ não implica necessariamente dispor de uma disciplina que nomeie essa teoria. Para trabalhar com ela, pode-se inseri-la de forma dispersa em diferentes programas que demandem o tipo de reflexão que ela oportuniza. Desse modo, é possível refletir sobre sintaxe à luz da AD, por exemplo. Basta, para tanto, fazer um trabalho comparativo entre os resultados de uma análise sintática com os resultados de uma análise discursiva de um mesmo material. Da mesma forma, o trabalho com a leitura e a produção textual permitem mobilizar o modo de reflexão próprio à $A D$. Penso, igualmente, que a Análise do Discurso seria de suma importância no momento em que os graduandos iniciam o planejamento de seu estágio. Vale dizer: o professor que está orientando a preparação da prática em sala de aula poderá sugerir atividades que mobilizem, não os conceitos teóricos da AD propriamente ditos, mas caminhos iluminados pela reflexão que a Análise do Discurso propicia.

A. R. - Sabemos que a $A D$, tal como foi proposta pelo francês Michel Pêcheux, vem hoje se desenvolvendo mais no Brasil que na França. E em relação a essa interface entre língua, discurso e ensino? Haveria na França, hoje, pesquisadores que têm se voltado para essa proposta de mobilizar a AD em sala de aula?

F. I. - Vou ficar devendo uma resposta bem fundamentada. "Acho" que não, mas, de fato, ignoro qualquer experiência neste sentido. E digo isso porque ninguém, hoje, na França, pratica a Análise do Discurso tal como formulada por Pêcheux. Lá, noções como ideologia, formação ideológica e formação discursiva, por exemplo, não são mais mobilizadas. $A$ AD, na França, foi higienizada e domesticada.

A. R. - Os professores têm sido alvo de críticas dentro da nova configuração política do país. Há grupos conservadores que consideram que professores que promovem debates e reflexões mais críticas em suas aulas são professores com "ideologia", "de esquerda", "de partido", etc. Qual o papel que um ensino de língua que mobilize a $A D$ em sala de aula pode desempenhar em tempos tão sombrios?

F. I. - Nestes tempos sombrios, é normal que os professores tenham medo de abordar certas questões em sala de aula. No entanto, como o que interessa é levar o aluno a trabalhar reflexivamente, é preciso buscar materiais que permitam desenvolver reflexão crítica sem expor-se excessivamente. Ou seja, não tomar nenhum tema que seja identificado como doutrinação. Eleger assuntos que permitam trabalhar criticamente, tomando posição, mesmo que seja algo que pareça "ingênuo". Por exemplo: O que fazer no carnaval: Brincar? Dançar? Desfilar? Sair 
em um bloco? Fazer um retiro? Formar uma coletânea de textos em torno de um mesmo assunto, mas com pontos de vista diversos. É possível, mesmo, a partir de uma discussão como essa, pedir aos alunos que tragam textos para formar um arquivo pedagógico ${ }^{21}$ e, a partir dele, trabalhar sem nomear, várias noções teóricas como ideologia, imaginário, tomada de posição, etc. Ou seja: é possível tomar qualquer tema "neutro" que se preste a ser olhado sob diferentes ângulos, como se fosse um caleidoscópio e, em torno deles, desenvolver o modo de trabalhar com a $A D$, pois o que interessa, de fato, é desenvolver a reflexão e a tomada de posição. Se o aluno souber fazer isso com temas "neutros" estará se exercitando para realizar algo semelhante com temas mais complexos.

\section{Sobre a entrevistada}

\section{Freda Indursky}

É licenciada em Letras pela UFRGS (1965). Possui Licence en Lettres - Faculté des Lettres et Sciences Humaines de Besançon (1967). Maîtrise en Lettres - Faculté des Lettres et Sciences Humaines de Besançon (1970). Doutora em Ciências da Linguagem pela Universidade Estadual de Campinas (1992). Professora Titular, aposentada, atua, como Professora Convidada, junto ao Programa de Pós-Graduação em Letras da Universidade Federal do Rio Grande do Sul. Seu projeto de pesquisa atual é "O papel das mídias na sociedade brasileira contemporânea", Publica em periódicos científicos nacionais e internacionais. Organizou vários livros e capítulos de livros. É autora dos livros $A$ fala dos quartéis e as outras vozes e $O$ discurso do/sobre o MST. Movimento social, sujeito, mídia.

\section{Sobre a entrevistadora}

\section{Andréa Rodrigues}

Andréa Rodrigues é doutora em Letras pela PUC-Rio (2001), com estágio de doutorado na École des Hautes Études em Sciences Sociales (França,1997) e Pós-Doutorado no Programa de PósGraduação em Memória Social da UNIRIO (2013). Fez Mestrado em Linguística (UFRJ, 1993) e Graduação em Letras (UFF, 1987). É professora da Graduação em Letras, do Programa de PósGraduação em Letras e Linguística (PPLIN) e do Mestrado Profissional em Letras (PROFLETRAS) da Faculdade de Formação de Professores da Universidade do Estado do Rio de Janeiro (FFPUERJ). Líder do grupo de pesquisa Núcleo de Estudos em Língua e Discurso (NELID). Atualmente, coordena a área de estudos linguísticos do PPLIN.

\footnotetext{
${ }^{21}$ INDURSKY, F. Leitura, escrita e ensino à luz da análise do discurso. In: NASCIMENTO, L. (org.). Presenças de Michel Pêcheux: da análise do discurso ao ensino. Campinas: Mercado de Letras, 2019b. p. $97-120$.
} 